\title{
Expression of Immunoreactive Cytidine 5'-Triphosphate: Cholinephosphate Cytidylyltransferase in Developing Rat Lung
}

\author{
RAMA K. MALLAMPALLI AND GARY W. HUNNINGHAKE
}

Pulmonary Division, Department of Internal Medicine, Department of Veterans Affairs Medical Center, and The University of Iowa College of Medicine, Iowa City. Iowa 52242

\begin{abstract}
The principle rate-limiting enzyme required for phosphatidylcholine production is cytidine $5^{\prime}$-triphosphate:cholinephosphate cytidylyltransferase. Two functional forms of cytosolic cytidylyltransferase have been previously identified: an active high-molecular weight multimer (H-form) and a relatively inactive low-molecularweight species ( $L$-form). In the present study, we examined the maturational changes in enzyme mass in the subcellular fractions of fetal, neonatal, and adult rat lungs. Total enzyme mass, measured by immunoblotting of total cellular lung homogenates, revealed a large amount of immunoreactive enzyme during the fetal and neonatal periods and relatively low levels of enzyme in the adult lung. A similar developmental profile for enzyme mass was noted in the cytosolic and microsomal fractions. Further, in the fetus, the majority of cytosolic enzyme mass was expressed as an inactive form (L-form). Stimulation of fetal cytosol with phosphatidylglycerol converted the enzyme mass from an inactive form ( $\mathrm{L}$-form) to an active form (H-form). In the adult, a substantial portion of the cytosolic enzyme mass was expressed as the active species (H-form). These observations suggest that cytidylyltransferase activity early in lung development is accompanied by an increase in enzyme mass, the majority of which exists as an inactive low-molecular-weight species. In contrast, high levels of enzyme activity are maintained in the adult lung, despite relatively low levels of enzyme mass, because a significantly greater portion of the enzyme mass is expressed as an active high-molecular-weight multimer. (Pediatr Res 34: 502-511, 1993)
\end{abstract}

\section{Abbreviations}

CTP, cytidine $5^{\prime}$-triphosphate

PMSF, phenylmethylsulfonyl fluoride

TBS, Tris-buffered saline

TTBS, TBS containing $0.05 \% \mathrm{vol} / \mathrm{vol}$ Tween 20

Lung development is characterized by a marked increase in the production of phosphatidylcholine, a major phospholipid constituent of cellular membranes and an essential component of pulmonary alveolar surfactant. The formation of cellular

Received November 24, 1992; accepted April 26, 1993

Correspondence: Rama K. Mallampalli, M.D., Pulmonary Division. C116. GH Department of Internal Medicine, University of Iowa College of Medicine, lowa City, IA 52242.

Supported by an institutional NRSA fellowship training grant (HL07638) from the National Heart, Lung, and Blood Institute; a Specialized Center of Research grant (SCOR, HL37121), and Grant RO-1 (HL43883) from the National Heart. Lung, and Blood Institute. membranes and induction of surfactant phospholipids are integral processes in maintaining alveolar structures and in generating an alveolar air-surface interface during perinatal development. The biosynthesis of phosphatidylcholine used in these processes appears to be highly regulated at the enzymatic level in mammalian systems.

CTP:cholinephosphate cytidylyltransferase (EC 2.7.7.15) is the principle rate-limiting enzyme required for phosphatidylcholine synthesis, catalyzing the conversion of cholinephosphate to cytidine $5^{\prime}$-diphosphate-choline via the cytidine $5^{\prime}$-diphosphatecholine pathway (1-4). In the lung, cytidylyltransferase activity may be detected in the microsomal and cytosolic subcellular fractions $(5,6)$. Cytosolic enzyme appears to exist both as an active high-molecular-weight lipoprotein aggregate ( $\mathrm{H}$-form $)$ and as a relatively inactive low-molecular-weight species ( $\mathrm{L}$-form) (710). Prior studies have demonstrated that cytidylyltransferase activity increases significantly during lung development, exhibiting a positive correlation with increased rates of surfactant phospholipid synthesis $(7,11-13)$.

The regulatory mechanisms underlying the developmental increase in cytidylyltransferase activity remain unclear. The increase in enzyme activity during development might be caused by an increase in the amount of cytidylyltransferase protein; however, limited data are currently available correlating enzyme activity with cytidylyltransferase mass. Alternative mechanisms proposed in various cell culture systems presumably involve an increase in the catalytic activity of preexisting enzyme rather than an increase in total enzyme mass. These mechanisms include dephosphorylation (14), membrane translocation-activation $(15,16)$, interconversion of $\mathrm{L}$-form to $\mathrm{H}$-form (17), and stimulation by fatty acids (18) and calcium (19). In the present study, we examined the maturational changes in cytidylyltransferase mass and correlated these observations with changes in activity of the enzyme in fetal, neonatal, and adult rat lung. We report that the fetal lung is characterized by a large amount of cytidylyltransferase enzyme mass; however, only a small fraction of this enzyme is in an active form (H-form). The amount of the active form (H-form) is significantly increased in the fetus after stimulation of the enzyme with phosphatidylglycerol. In marked contrast, the adult lung has a much smaller mass of enzyme, but this enzyme mass is in a more active form (H-form).

\section{MATERIALS AND METHODS}

Animals. Pregnant Sprague-Dawley rats of timed-gestational ages (d 18, d 20, and d 22), developmentally staged neonatal rats, and 3- and 6-wk-old adult rats (weighing 150-200 g) were purchased from Charles River Laboratories, Wilmington, MA. All animals were given unrestricted access to food and water and allowed to acclimate in virus-free housing $1 \mathrm{wk}$ before use.

Materials. Phosphatidylcholine (from egg yolk), phosphatidylglycerol, oleic acid, CTP, octyl glucoside, activated charcoal, 


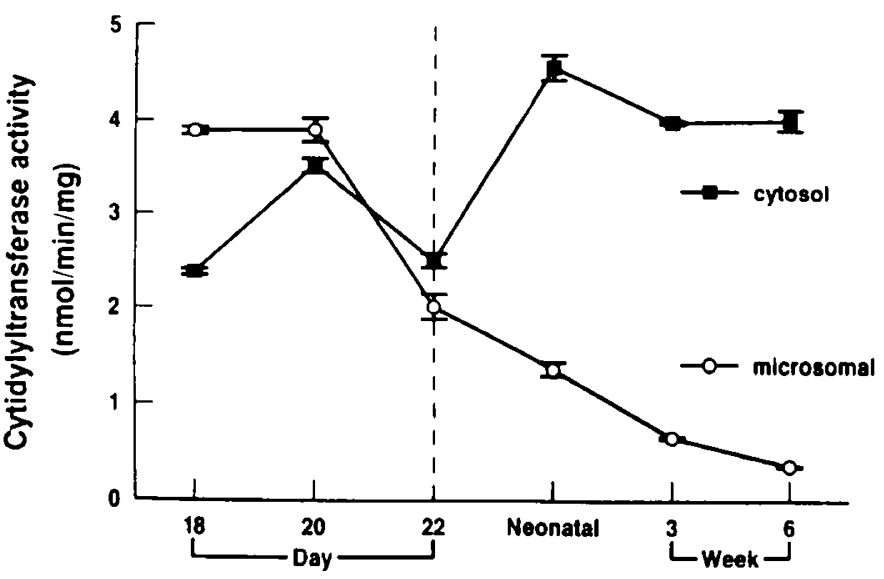

Fig. 1. The activity of CTP:cholinephosphate cytidylyltransferase in the cytosolic and microsomal fractions during rat lung development. Enzyme activity was assayed in the presence of phosphatidylcholine:oleic acid (a 1:1 molar ratio) in the reaction mixture. The activities represent the mean \pm SEM of three separate assays.

staphylococcal protein A, phosphorylcholine chloride, PMSF, DTT, and rabbit antichicken polyclonal $\mathrm{IgG}$ were purchased from Sigma Chemical Co. (St. Louis, MO). The nitrocellulose membranes and Bradford reagents were purchased from BioRad (Richmond, CA). Centricell filters for protein concentration were obtained from Polysciences. Inc. (Warrington, PA). The ${ }^{14} \mathrm{C}$ phosphorylcholine $(50 \mu \mathrm{Ci} / \mathrm{mmol})$ and ${ }^{125} \mathrm{I}$ protein $\mathrm{A}(100 \mu \mathrm{Ci} /$ $\mathrm{mL}$ ) were purchased from DuPont-New England Nuclear Chemicals (Dreieich, Germany). The ${ }^{14} \mathrm{C}$-radiolabeled protein standards for SDS-PAGE were obtained from Amersham Corp. (Arlington Heights, IL). The Superdex 16/60 prep grade media, column, and chromatography standards were purchased from Pharmacia Fine Chemicals (Uppsala, Sweden). Polyclonal cytidylyitransferase antiserum was a generous gift of Dr. D. E. Vance (Department of Biochemistry, University of Alberta, Edmonton, Canada).

Preparation of subcellular fractions. Pregnant rats of timed gestational ages were anesthetized by intraperitoneal injection with phenobarbital $(50 \mathrm{mg} / \mathrm{kg})$. Rat fetuses were surgically removed from their mothers and fetal lungs were resected. Lungs from neonatal and adult rats were also surgically isolated. All organs were homogenized at $5 \mathrm{~mL} / \mathrm{g}$ tissue in buffer $\mathrm{A}(150 \mathrm{mM}$ $\mathrm{NaCl}, 50 \mathrm{mM}$ Tris, $1.0 \mathrm{mM}$ EDTA, $2 \mathrm{mM}$ DTT, $0.025 \%$ sodium azide, $1 \mathrm{mM}$ PMSF, $\mathrm{pH} 7.4$ ) using a motor driven homogenizer at $4^{\circ} \mathrm{C}$ as previously described (20). The cytosolic fraction was obtained after centrifugation at $10000 \times g$ for $10 \mathrm{~min}$ and $125000 \times g$ for $60 \mathrm{~min}$. The microsomal pellet recovered after the second spin was resuspended in buffer $\mathrm{R}[10 \mathrm{mM}$ Tris- $\mathrm{HCl}$, pH 7.4, 0.25 M sucrose, and 0.1 mM PMSF (21)].

Cytidylyltransferase activity. Enzyme activity was determined by measuring the rate of methyl- ${ }^{14} \mathrm{C}$ phosphocholine incorporation into CDP-choline using a charcoal extraction procedure essentially as described by Weinhold $e t$ al. (20). Briefly, each reaction mixture contained $1.6 \mathrm{mM}$ methyl- ${ }^{14} \mathrm{C}$ phosphocholine, $3.0 \mathrm{mM}$ CTP, $12 \mathrm{mM} \mathrm{Mg}$ acetate, $50 \mathrm{mM}$ imidizole, $150 \mathrm{mM}$ $\mathrm{KCl}, 2$ mM EDTA, pH 7.0, and, where indicated, a 1:1 molar ratio of lipid activator. The lipid activator consisted of a mixture of oleic acid:phosphatidylcholine in a 1:1 molar ratio. The final concentration of each lipid was $500 \mu \mathrm{m}$ in the reaction mixture. Reactions contained a total assay volume of $100 \mu \mathrm{L}$, proceeded for $1 \mathrm{~h}$ at $37^{\circ} \mathrm{C}$, and were terminated using $10 \%$ trichloroacetic acid and $6 \%$ charcoal. Reaction rates were linear with respect to time and the amount of enzyme present in the assay mixture. The recovery of CDP-choline using this method in our laboratory is approximately $71 \%$.

Protein analysis. Protein concentrations were determined using the Bradford method (22). BSA was used as a protein standard.

Gel electrophoresis. SDS-PAGE was performed as described by Laemmli (23). Resolving gels consisted of $10 \%$ acrylamide, $0.375 \mathrm{M}$ Tris- $\mathrm{HCl}, \mathrm{pH} 8.8$, and $0.1 \%$ SDS. Stacking gels were prepared with $0.125 \mathrm{M}$ Tris- $\mathrm{HCl}, 3.75 \%$ acrylamide, $\mathrm{pH} \mathrm{6.8,} \mathrm{and}$ $0.1 \%$ SDS. Gel polymerization was obtained using ammonium persulfate as the catalyst and $N, N, N^{\prime}, N^{\prime}$-tetramethylethylenediamine. Protein sample buffer consisted of $0.0625 \mathrm{M}$ Tris- $\mathrm{HCl}$ (pH 6.8), 10\% glycerol, 5\% 2-mercaptoethanol, 2\% SDS and $0.002 \%$ bromophenol blue. Reservoir buffer consisted of 0.025 M Tris, $0.192 \mathrm{M}$ glycine, and $0.1 \%$ SDS. Protein samples were denatured before electrophoresis by heating at $95^{\circ} \mathrm{C}$ for 5 to 7 $\min$. Protein samples were electrophoresed at a constant current of 10-12 mA until the dye front reached the bottom of the gel.

Partial purification of cytidylyltransferase from rat liver. Cytidylyltransferase was partially purified from cytosolic preparations of adult rat livers using $\mathrm{N}$-octyl glucoside as described previously (20).

Isolation of $H$-form and $L$-form by gel filtration. Cytidylyltransferase $\mathrm{H}$-form and $\mathrm{L}$-form species were isolated from fetal (d 20), neonatal, and adult lung cytosol by gel filtration chromatography using a Superdex column $(1.6 \times 60 \mathrm{~cm})$ equilibrated with buffer A. Approximately $21 \mathrm{mg}$ of cytosolic protein were applied to the column, which was eluted at a linear flow rate of $0.375 \mathrm{~mL} / \mathrm{min}$ at $4^{\circ} \mathrm{C}$ for optimal resolution. Eluted fractions $(1.5 \mathrm{~mL})$ with approximate molecular weight ranges corresponding to cytidylyltransferase $\mathrm{H}$-form and $\mathrm{L}$-form were collected, pooled, and concentrated using Centricell ultrafilters. The molecular sizes for these fractions were estimated by using the following calibration standards: blue dextran $2 \times 10^{6} \mathrm{D}$, thyroglobulin $669000 \mathrm{D}$. catalase $232000 \mathrm{D}$, albumin $67000 \mathrm{D}$, and chymotrypsinogen $25000 \mathrm{D}$. In addition, confirmation of the $\mathrm{H}$-form and L-forms of cytidylyltransferase in these fractions was performed by demonstrating the characteristic lipid sensitivities of these species (7). All concentrates were stored at $4^{\circ} \mathrm{C}$ before gel electrophoresis and determination of enzyme activity as described above.

Immunodetection of cytidylyltransferase. Total cellular, cytoplasmic, microsomal, and immunoreactive $\mathrm{H}$-form and $\mathrm{L}$-form cytidylyltransferase was determined by Western blot analysis as previously described $(21,24)$. After separation using SDS-PAGE, the proteins were electroblotted to a $0.45-\mu \mathrm{m}$ nitrocellulose filter at a constant voltage of $25 \mathrm{~V}$ overnight as described by Towbin et al. (25). The electroblotting buffer consisted of $0.025 \mathrm{M}$ Tris, $0.192 \mathrm{M}$ glycine, and $20 \% \mathrm{vol} / \mathrm{vol}$ methanol, $\mathrm{pH} 8.3$. After transfer, the filter was washed with a solution of TBS $(20 \mathrm{mM}$ Tris, $500 \mathrm{mM} \mathrm{NaCl}, \mathrm{pH} \mathrm{7.5),} \mathrm{blocked} \mathrm{for} 2 \mathrm{~h}$ with TBS containing $3 \%$ gelatin, and then washed twice with TTBS. The filter was then labeled with chicken cytidylyltransferase polyclonal antibody [1:500 dilution in TTBS (21)] kindly provided by Dr. D. E. Vance, for $8 \mathrm{~h}$, washed twice with TTBS, and labeled with rabbit antichicken IgG (1:1000 dilution in TTBS) for $2 \mathrm{~h}$. After rinsing, the antibody-protein conjugates were immunolabeled with ${ }^{125}$ I-protein $A$ for $1 \mathrm{~h}$ and the label was visualized after exposure to Kodak XAR2 radiographic film for $4 \mathrm{~h}$ at $-70^{\circ} \mathrm{C}$. Western blot analysis for the detection of cytidylyltransferase protein was linear in the range from $300 \mu \mathrm{g}$ to $10 \mu \mathrm{g}$ as determined by densitometry of the immunoblots.

Activation of cytidylyltransferase by phosphatidylglycerol. Stock solutions of phosphatidylglycerol (from egg yolk) were prepared as described previously (26). Fetal (d 20) and neonatal cytosols at protein concentrations of approximately $8 \mathrm{mg} / \mathrm{mL}$ were incubated at $37^{\circ} \mathrm{C}$ for $30 \mathrm{~min}$ with freshly sonicated phosphatidylglycerol in a final lipid concentration of $0.4 \mathrm{mM}$ (26). After incubation, the lipid mixtures were subjected to gel filtration chromatography and eluted fractions were assayed for cytidylyltransferase $\mathrm{H}$-form and L-form activity and enzyme mass as described above. 

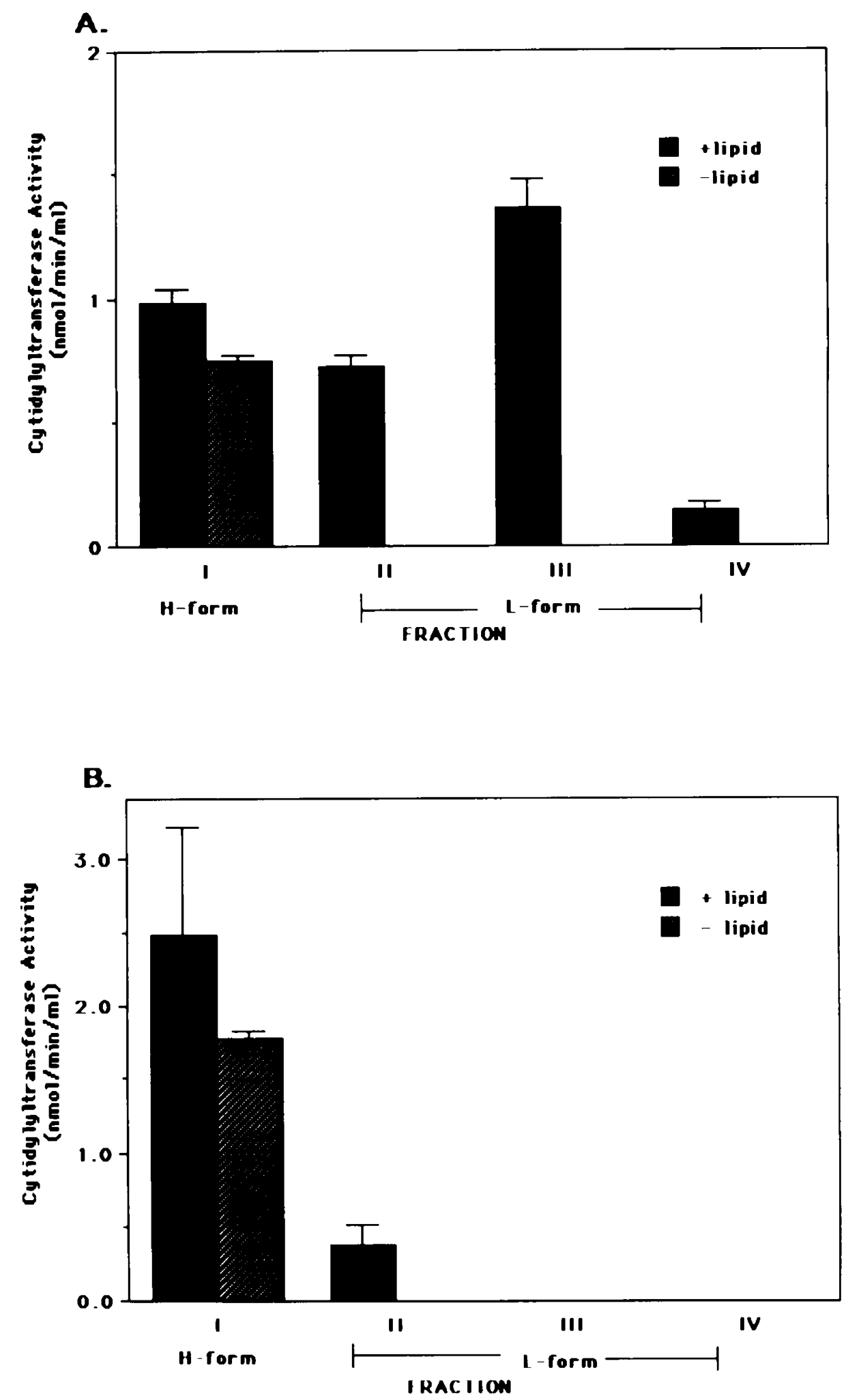

Fig. 2. The activities of CTP:cholinephosphate cytidylyltransferase $\mathrm{H}$-form (fraction I) and L-form (fractions II, III, and IV) as measured in eluted fractions after separation of fetal (d 20) $(A)$ and adult $(B)$ lung cytosol (approximately $21 \mathrm{mg}$ ) using gel filtration chromatography. Enzyme activity was assayed both in the presence and absence of the lipid activator phosphatidylcholine:oleic acid (a 1:1 molar ratio) in the reaction mixture. The activities represent the mean \pm SEM of three separate experiments. Each experiment consisted of lungs isolated from three litters or two adult rats.

\section{RESULTS}

Cytidylyltransferase activity. Enzyme activity was determined during the fetal, neonatal, and adult periods in the cytosolic and microsomal subcellular fractions and in $\mathrm{H}$-form and L-form fractions after gel filtration chromatography of fetal and adult lung cytosol. $\mathrm{Sp}$ act of cytidylyltransferase measured in the $100000 \times$ supernatant fraction revealed a modest rise in activity early in gestation, followed by a small decrease in enzyme activity at term (d 22). Enzyme activity increased nearly 2 -fold during 
A.

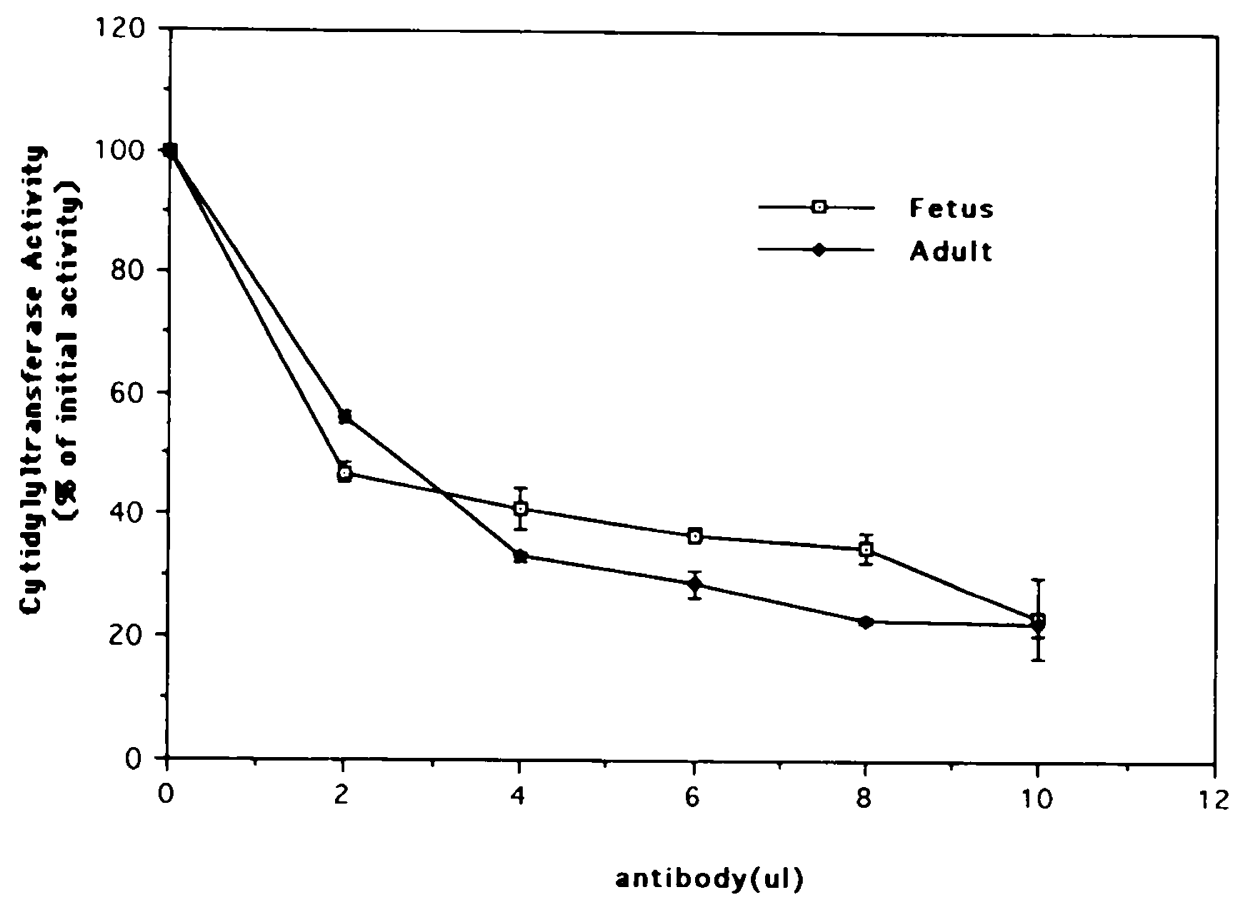

B.

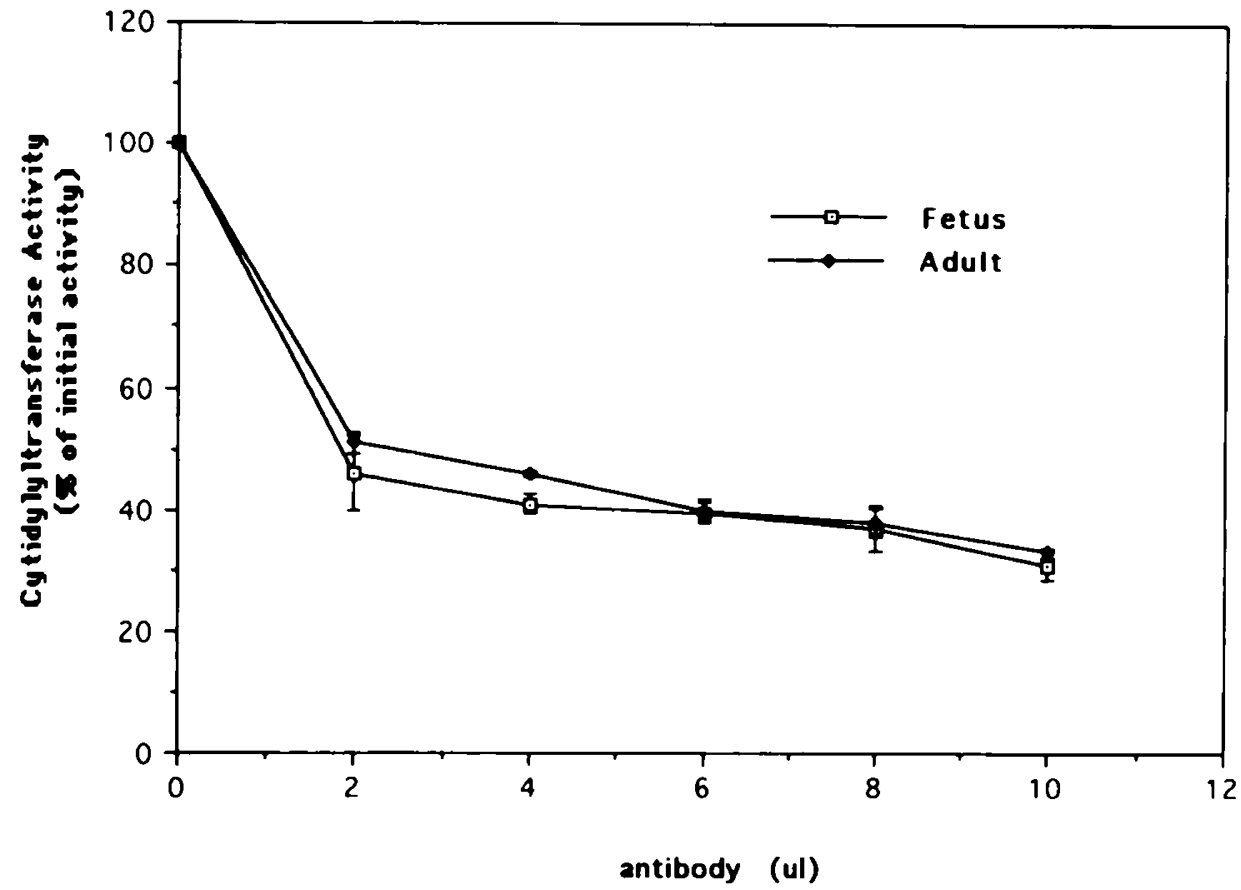

Fig. 3. Immunotitration of cytidylyltransferase activity. Aliquots containing constant amounts of cytidylyltransferase antigen from fetal and adult lung cytosol $(A)$ and microsomes $(B)$ were incubated with variable amounts of chicken polyclonal cytidylyltransferase antibody for $16 \mathrm{~h}$ at $4^{\circ} \mathrm{C}$. Each aliquot was labeled with a rabbit antichicken antibody for $24 \mathrm{~h}$, followed by immunoprecipitation for $1 \mathrm{~h}$ with a $10 \%$ staphyloccocal protein A solution previously suspended in buffer A. The total volume of the reaction mixture was $60 \mu \mathrm{L}$. The immunoprecipitated pellet was removed by sentrifugation at $10000 \times g$ for $15 \mathrm{~min}$, and $20 \mu \mathrm{L}$ of supernatant was then assayed for enzyme activity. Enzyme activity was assayed in the presence of phosphatidylcholine:oleic acid (a 1:1 molar ratio) in the reaction mixture. 


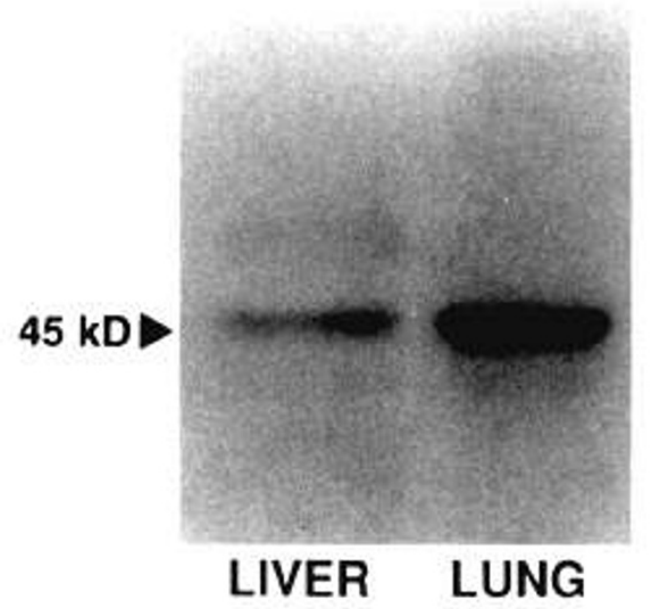

Fig. 4. Comigration of lung with liver CTP:cholinephosphate cytidylyltransferase as demonstrated by Western blotting. The left lane was loaded with partially purified cytidylyltransferase from the N-octyl glucoside extract (20) and the right lane with fetal lung homogenate $(50 \mu \mathrm{g})$. A chicken polyclonal antibody originally raised against partially purified liver enzyme was used in the immunoblotting.

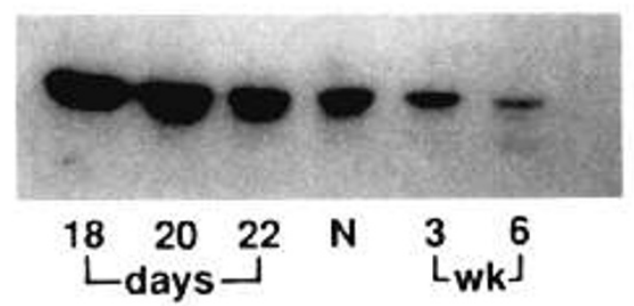

Fig. 5. Western blotting demonstrating the amount of CTP: cholinephosphate cytidylyltransferase in whole lung homogenates during lung development. Each lane was loaded with an equal amount of homogenate protein $(200 \mu \mathrm{g})$. separated on a $10 \%$ polyacrylamide gel in SDS, and labeled with chicken polyclonal antibody to cytidylyltransferase (see Materials and Methods). The data are representative of three experiments.

the neonatal period (Fig. 1). Cytosolic activity subsequently plateaued in the 3-and 6-wk adult lung. In addition, gel filtration chromatography of fetal and adult lung cytosol revealed that enzyme activity was recovered in four eluted fractions: highmolecular-weight $\mathrm{H}$-form (fraction I) and low-molecular-weight L-forms (fractions II, III, and IV) corresponding to molecular sizes of approximately $>2 \times 10^{6}$ [fraction I (void volume)], 232 000-669 000 (fraction II), $117000-219000$ (fraction III), and 52 000-105000 (fraction IV). We assayed for enzyme activity in these fractions, both with and without the addition of a lipid activator directly to the reaction mixture (Fig. $2 A$ and $B$ ). As shown in Figure 2 , the majority of cytosolic enzyme activity was detected in the $\mathrm{H}$-form fractions for adult cytidylyltransferase; enzyme activity was observed at only low levels in the Lform fractions. When assayed with the addition of lipid to the assay mixture, $\mathrm{H}$-form fraction I contained over $86 \%$ of the activity in adult lung cytosol (Fig. $2 B$ ). Further, the majority of this enzyme activity was still detected in this fraction even when the assay was performed in the absence of lipid activator (Fig. $2 B$ ). By contrast, in the fetus, cytosolic enzyme activity in the presence of lipid was distributed primarily in the L-form fractions (Fig. $2 A$ ). L-form fraction III contained the major portion (approximately $43 \%$ ) of the total eluted activity (Fig. $2 A$ ). In the absence of lipid in the assay mixture, cytidylyltransferase activity in these L-form fractions was undetectable. Microsomal cytidylyltransferase activity was high in the fetus (d 18 and 20) and, thereafter, progressively declined to low levels in the adult rat lung (Fig. 1).
Immunotitration of cytidylyltransferase activity. The effect of the cytidylyltransferase antiserum on inhibiting lung cytosolic and microsomal activity was evaluated using immunotitration. The antiserum was previously raised in the chicken after immunization with partially purified liver enzyme $(21,27)$. Incubation of aliquots containing constant amounts of cytidylyltransferase antigen with increasing amounts of chicken polyclonal antibody revealed that enzyme activity was significantly inhibited in both fetal and adult lung cytosol (Fig. 3A). The chicken polyclonal antibody neutralized fetal cytosolic activity by $74 \%$ and nearly $80 \%$ in adult lung cytosol. A similar effect was observed by the antibody against microsomal activity (Fig. $3 B$ ).

Comigration of lung with liver cytidylyltransferase. The chicken polyclonal antibody reacted with cytidylyltransferase from liver and lung and the enzyme appeared to be identical by immunoblot studies in both of these tissue preparations. Immunoblotting revealed that the antiserum detected the partially purified enzyme from adult rat liver cytosol (Fig. 4). Further, the immunoreactive band from liver appeared to comigrate with cytidylyltransferase from fetal lung homogenate (Fig. 4).

Immunodetection of cytidylyltransferase. The amount of cytidylyltransferase protein was determined by immunoblotting of whole lung homogenates and cytosolic and microsomal subcellular fractions at similar developmental stages in which enzyme activities were previously measured. Immunoblotting of rat whole lung homogenates using chicken polyclonal cytidylyltransferase antibody revealed a large amount of enzyme mass during the early stages of fetal lung development [d 18 and 20 (Fig. 5)]. Enzyme mass was observed to gradually diminish in each successive developmental period and was detected at relatively low levels in the adult lung. Cytosolic enzyme was also expressed at high levels during the fetal period (d 18-22) and gradually declined in the neonatal and adult lung, exhibiting a developmental profile similar to that of whole lung homogenates (Fig. $6 \mathrm{~A}$ ). Microsomal fractions had detectable levels of enzyme in the fetus (d 18 and 20); however, cytidylyltransferase was undetectable during latter stages of lung development (Fig. 6B). The relative changes in cytosolic enzyme mass and activity in fetal $(d$ 20) and adult lung are further illustrated in Figure 7.

Immunodetection of $H$-form and $L$-form. Total immunoreactive $\mathrm{H}$-form and $\mathrm{L}$-form cytidylyltransferase were measured in eluted fractions after chromatographic separations of fetal (d 20) and adult lung cytosol. Immunoblotting of fetal cytosolic fractions revealed that the majority of fetal enzyme mass was detected in fraction III as L-form enzyme (Fig. 8). In addition, a substantial amount of immunoreactive enzyme mass was also distributed in L-form fraction II (Fig. 8). Cytosolic fraction I, however, expressed only very low levels of fetal $\mathrm{H}$-form protein despite the fact that significant levels of enzyme activity were observed in this fraction.

Adult cytosolic enzyme mass was detected primarily in the relatively higher molecular size fractions. The majority of the enzyme in adult lung was recovered in fraction II; however, compared with fetal lung, a greater portion of total cytosolic enzyme mass was detected in $\mathrm{H}$-form fraction I (Fig. 8). In marked contrast to fetal lung, the amount of immunoreactive Lform species as measured in fraction III was expressed at very low levels in adult lung cytosol (Fig. 8).

The amounts of $\mathrm{H}$-form and L-form cytidylyltransferase as demonstrated above by immunoblotting were further analyzed for $\mathrm{sp}$ act ( $\mathrm{nmol} / \mathrm{min} / \mathrm{mass}$ unit) using densitometric measurements of enzyme mass (Table 1). The sp act of cytidylyltransferase both in fetal and adult lung cytosol was observed to be highest in $\mathrm{H}$-form fraction I. Relatively low levels of $\mathrm{sp}$ act were detected in the L-form fractions of the fetus and adult.

Activation of cytidylyltransferase by phosphatidylglycerol. The effect of phosphatidylglycerol on cytidylyltransferase $\mathrm{H}$-form and L-form enzyme activity and enzyme mass was evaluated by incubating fetal and neonatal cytosolic preparations with phosphatidylglycerol, followed by isolation of these cytosolic forms 
A.

CYTOSOLIC

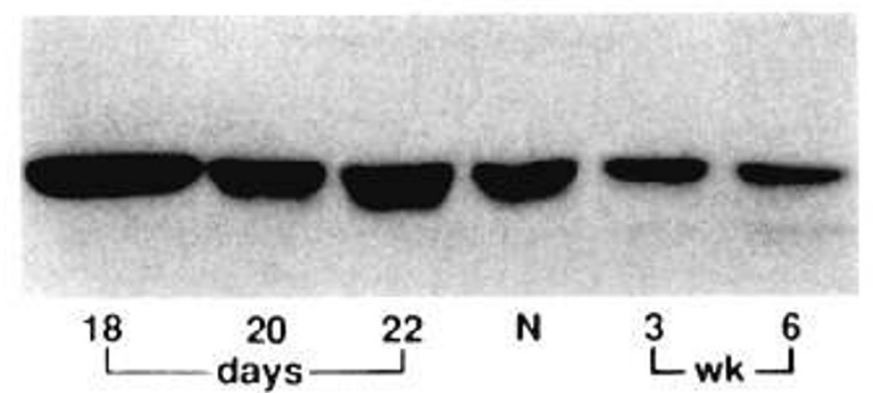

B.

MICROSOMAL

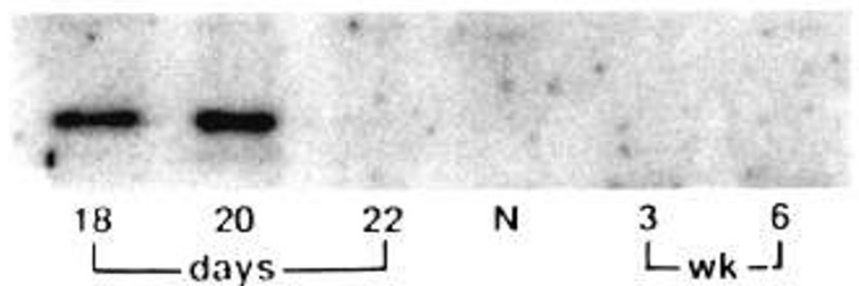

Fig. 6. Western blotting demonstrating the amount of CTP:cholinephosphate cytidylyltransferase in the cytosolic ( $A)$ and microsomal ( $B)$ fractions during rat lung development. Each lane was loaded with an equal amount of cytosolic $(200 \mu \mathrm{g})$ or microsomal (100 $\mu \mathrm{g})$ protein. Proteins were separated and the amount of cytidylyltransferase protein was determined as described for whole-lung homogenate. The data are representative of three experiments.

by chromatography. In the fetus, phosphatidylglycerol shifted the activity profile from the relatively lower molecular weight fractions (fractions II and III) to $\mathrm{H}$-form fraction I (Fig. 9). The previously observed activity in L-form fraction III isolated from control cytosols was no longer detected after stimulation with phospholipid. In addition, phosphatidylglycerol decreased activity in fraction II by nearly $47 \%$ and markedly increased activity in fraction I by $54 \%$ relative to control fractions (Fig. 9). The redistribution of activity induced by phosphatidylglycerol in fetal cytosol was associated with similar changes in enzyme mass (Fig. 10). The relatively large amount of immunoreactive enzyme observed in fraction II and fraction III from control fetuses was not detected in fractions isolated from phosphatidylglycerolstimulated cytosols. This enzyme mass was redistributed, in part, to $\mathrm{H}$-form fraction $\mathrm{I}$, where a 2 -fold increase in the level of enzyme mass was detected (Fig. 10).

In the neonatal lung, phosphatidylglycerol also had significant effects on the distribution of the cytosolic forms of the enzyme. Stimulation of neonatal cytosol by phosphatidylglycerol resulted in a marked shift in the amount of enzyme protein from the relatively lower molecular weight fractions (fraction II, fraction III) to $\mathrm{H}$-form fraction $\mathrm{I}$ (Fig. 11).

Phosphatidylglycerol also redistributed enzyme activity in these cytosolic fractions, although these effects by comparison were relatively small. The majority of cytidylyltransferase activity in neonatal control cytosols was detected in $\mathrm{H}$-form fraction $\mathrm{I}$ (Fig. 12). Phosphatidylglycerol induced a shift in enzyme activity from fraction II to fraction I, and these changes were associated with a net increase in the level of activity in fraction I by only 9\% (Fig. 12).

\section{DISCUSSION}

Previous studies have shown that there is a pronounced increase in total lung cytidylyltransferase activity during the peri- natal period with enzyme activity increasing several fold either during the late alveolar stage (d 22) of fetal lung growth $(5,28)$ or immediately postbirth in the neonate $(7,12,13)$. The majority of this activity reflects activity in the cytosolic fraction of lung tissue $(7,13)$. It has also been shown that cytidylyltransferase activity in the microsomal fraction is higher in the fetal lung compared with the adult lung (13). The findings of the present report are consistent with these prior observations. The purpose of these studies, however, was to determine whether developmental changes in cytidylyltransferase activity were caused by similar changes in enzyme mass. We found that the increases in cytidylyltransferase activity associated with maturation are not mediated by an increase in enzyme mass. In fact, total enzyme mass is highest during the earlier stages of fetal development.

Our studies, as well as prior studies $(5,7,13)$, demonstrate that the relative amounts of cytidylyltransferase activity in the cytosolic tissue fraction compared with the microsomal fraction of lung tissue change markedly as a function of maturation. $\mathrm{Sp}$ act of cytosolic enzyme increases significantly from the glandular (d 18) to the neonatal (saccular) stage. During this period, the biosynthesis of lung phosphatidylylcholine is critical to facilitate a 3-fold increase in the alveolar surface area (29) and to expand nearly 7-fold the biochemical pool of surfactant phospholipid (30). We observed a transient decrease in cytosolic enzyme activity that occurred at term gestation (d 22), a finding that has been reported previously (12). In the adult lung. cytosolic enzyme remained at relatively high levels compared with the early gestational period. Microsomal enzyme activity, by contrast, substantially declined during successive periods of lung maturation, reaching very low levels in the adult lung.

Weinhold et al. (31) previously reported that cytosolic enzyme activity can exist as a highly active lipid-associated multimer $(\mathrm{H}$ form) and as a lipid-independent species (L-form); both species contain the catalytic protein subunit. The molecular weights of these subcellular forms of cytidylyltransferase were estimated. 


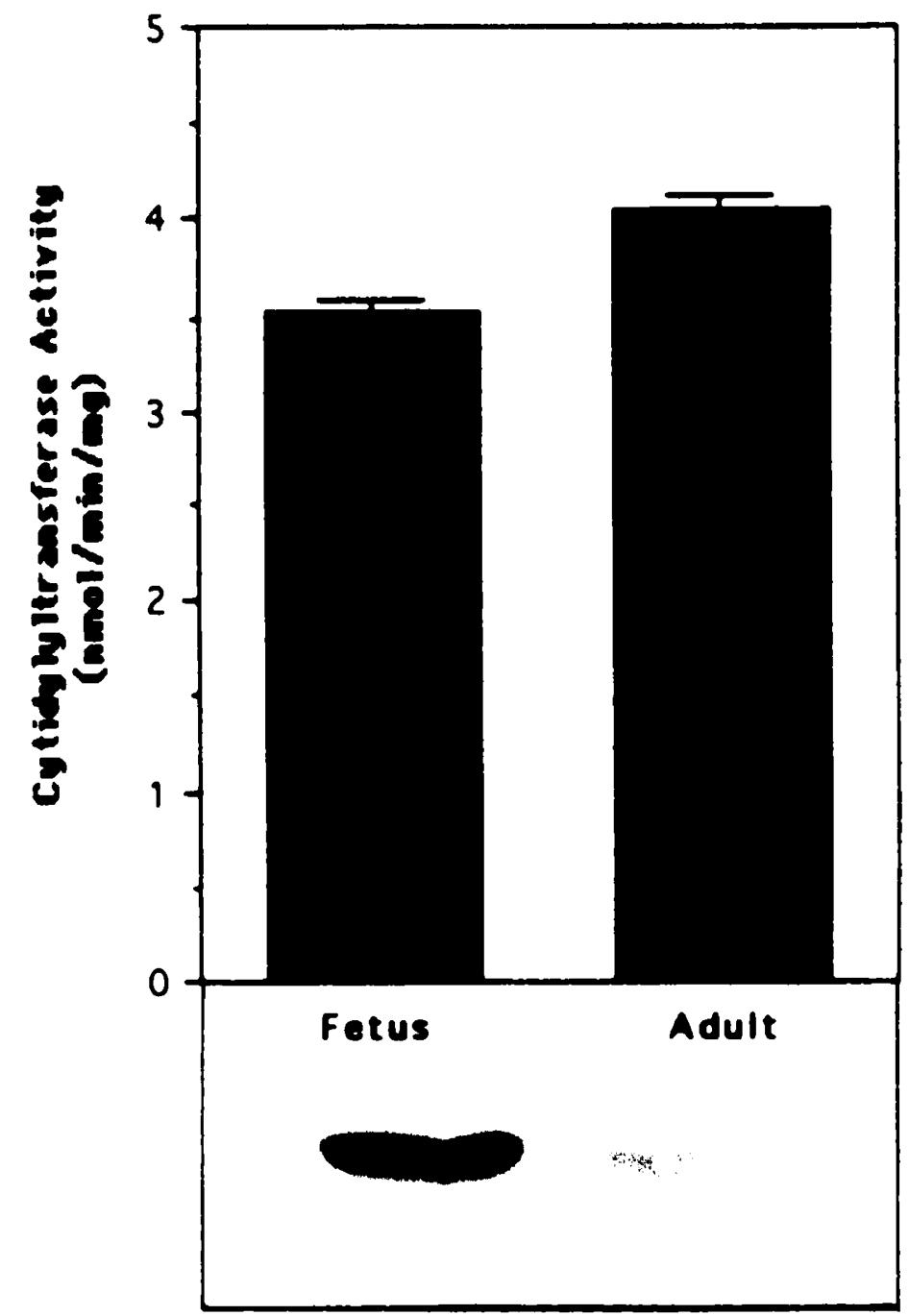

Fig. 7. Relative expression of CTP:cholinephosphate cytidylyltransferase in fetal (d 20) and adult rat lung. The har graph represents sp act in lung cytosol. The amount of enzyme mass in the fetus and adult is illustrated in the b/ot below. Enzyme mass was detected using a chicken polyclonal antibody. Each lane was loaded with $200 \mu \mathrm{g}$ of cytosolic protein.

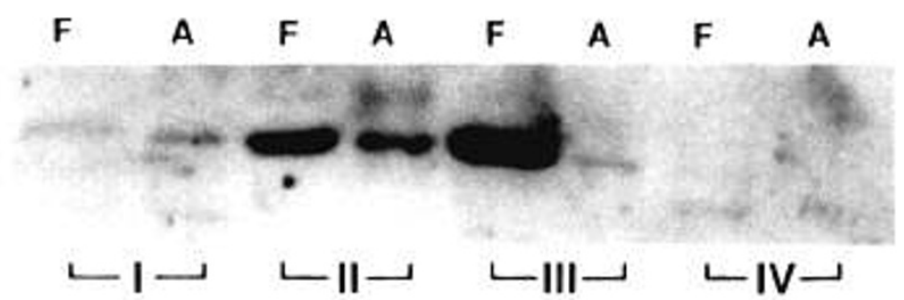

Fig. 8. Western blotting demonstrating the amount of CTP:cholinephosphate cytidylyltransferase enzyme mass expressed in H-form (fraction I) and L-form (fractions II, III, and IV) fractions after separation of fetal $(F)$ and adult $(A)$ lung cytosol (approximately $21 \mathrm{mg}$ ) by gel filtration chromatography. Lanes were loaded with equal amounts of protein $(50 \mu \mathrm{g})$ and assayed as described in Materials and Methods. The data are representative of three experiments.

using gel filtration, to be approximately $5 \times 10^{6} \mathrm{D}$ for $\mathrm{H}$-form enzyme and $190000 \mathrm{D}$ for L-form enzyme (9). Other studies, using sedimentation coefficients, suggested that the molecular weight of the $\mathrm{H}$-form was approximately $284000 \mathrm{D}$ and that of the L-form was about $97690 \mathrm{D}(31)$. In the present investigation. cytidylyltransferase activity was assayed in fractions with molecular weight ranges corresponding to molecular size estimates as determined by both these methods. Our results are in agreement with these prior studies and indicate that the majority of enzyme activity in adult lung cytosol is expressed primarily by the $\mathrm{H}$ form species (7). In the adult, nearly $90 \%$ of the enzyme activity was expressed as the $\mathrm{H}$-form enzyme. In the fetus, however. enzyme activity was primarily distributed in the L-form fractions. with nearly $70 \%$ of the cytosolic activity detected as L-form enzyme. Unlike H-form enzyme, the enzyme in these L-form fractions was in an inactive form, inasmuch as activity was detected only with the addition of a lipid activator to the assay mixture (Fig. 2). Together these findings suggest that cytosolic enzyme activity during lung maturation is converted from a relatively inactive low-molecular-weight species to an active highmolecular-weight lipoprotein complex.

Previous studies, to our knowledge, have not evaluated cytidylyltransferase mass as a function of lung maturation and correlated these findings with amounts of enzyme activity in 
Table 1. Cytosolic distribution of cytidy/yltransferase activity $(\mathrm{nmol} / \mathrm{min} / \text { mass unit })^{*}$

\begin{tabular}{crrccc}
\multicolumn{2}{c}{ H-form } & \multicolumn{4}{c}{ L-form } \\
\cline { 1 - 3 } \cline { 5 - 6 } Fraction & I & & II & III & IV \\
Fetal & $33.9 \pm 0.67$ & & $0.36 \pm 0.0$ & $0.35 \pm 0.0$ & $0.53 \pm 0.01$ \\
Adult & $5.2 \pm 0.03$ & & $0.05 \pm 0.0$ & $0.02 \pm 0.0$ & $0.00 \pm 0.00$
\end{tabular}

* Sp ac are expressed as enzyme activity/enzyme mass $[(\mathrm{nmol} / \mathrm{min} /$ $\mathrm{mg}$ of total lung protein) $/($ mass units $/ \mathrm{mg}$ of total lung protein $)=\mathrm{nmol} /$ $\mathrm{min} / \mathrm{mass}$ unit]. Mass units were arbitrary values as determined by densitometric analysis of immunoblots.

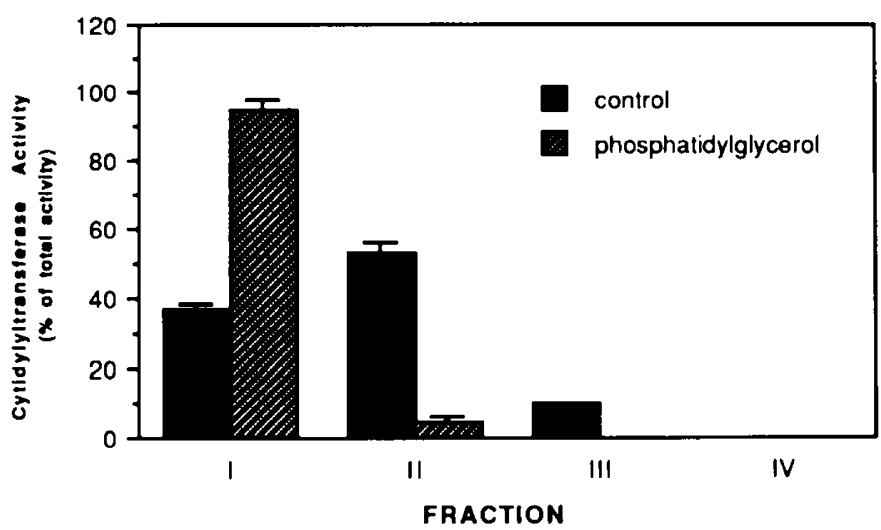

Fig. 9. Effect of phosphatidylglycerol on fetal cytidylyltransferase $\mathrm{H}$ form and L-form activity. Fetal lung cytosol was incubated for $30 \mathrm{~min}$ at $37^{\circ} \mathrm{C}$ with sonicated phosphatidylglycerol $(0.4 \mathrm{mM})$, and $\mathrm{H}$-form and L-form species were then isolated and assayed for enzyme activity. Enzyme activity was assayed in the presence of phosphatidylcholine:oleic acid (a 1:1 molar ratio) in the reaction mixture. The data are representative of three experiments.

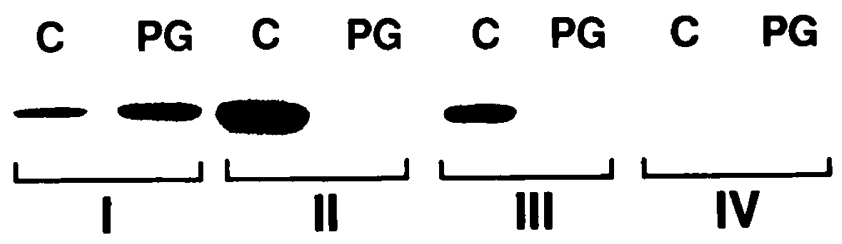

Fig. 10. Effect of phosphatidylglycerol on fetal cytidylyltransferase $\mathrm{H}$ form and L-form enzyme mass. Fetal lung cytosol was incubated for 3 min at $37^{\circ} \mathrm{C}$ with sonicated phosphatidylglycerol, and $\mathrm{H}$-form and Lform species were then isolated and assayed for enzyme mass. Each lane was loaded with $50 \mu \mathrm{g}$ of eluted protein. $C$, control: $P G$, phosphatidylglycerol. The data are representative of three experiments.

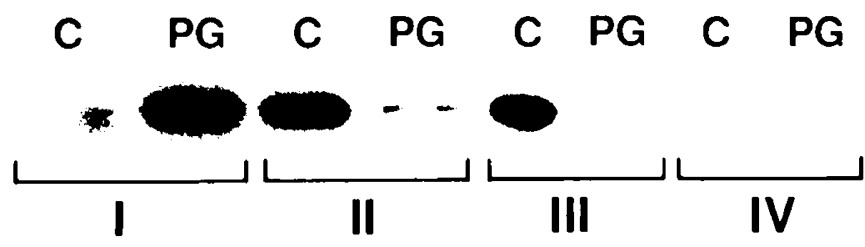

Fig. 11. Effect of phosphatidylglycerol on neonatal cytidylyltransferase $\mathrm{H}$-form and $\mathrm{L}$-form enzyme mass. Neonatal lung cytosol was incubated with phosphatidylglycerol (see Materials and Methods), and Hform and L-form species were then isolated and assayed for enzyme mass. Each lane was loaded with $50 \mu \mathrm{g}$ of eluted protein. $C$, control; $P G$, phosphatidylglycerol. The data are representative of three experiments.

pulmonary tissues. In the present study, enzyme mass in the lung was measured using a chicken polyclonal antiserum that was previously shown to react with the cytosolic forms of liver enzyme (21). Although the antiserum was initially raised against liver cytidylyltransferase, it was observed to effectively neutralize lung cytidylyltransferase activity in both fetal and adult cytosolic

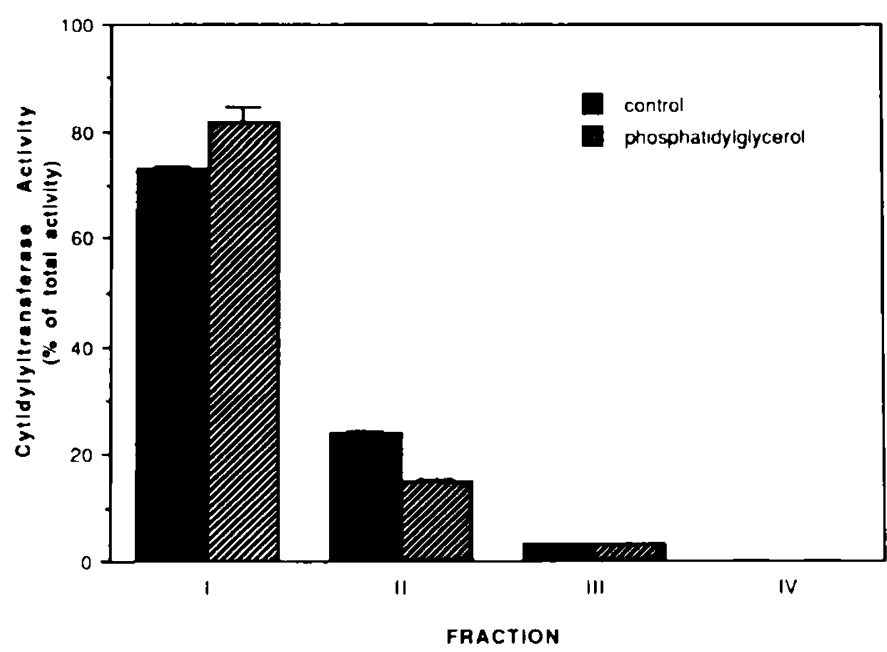

Fig. 12. Effect of phosphatidylglycerol on neonatal cytidylyltransferase $\mathrm{H}$-form and L-form activity. Neonatal lung cytosol was incubated with phosphatidylglycerol (see Materials and Methods), and H-form and L-form species were then isolated and assayed for enzyme activity. Enzyme activity was assayed in the presence of phosphatidylcholine:oleic acid (a 1:1 molar ratio) in the reaction mixture. The data are representative of three experiments.

and microsomal preparations (Fig. 3). Immunoblotting experiments using this antibody demonstrated comigration of lung enzyme with partially purified liver cytidylyltransferase (Fig. 4), suggesting that these proteins are immunologically similar. Our results further demonstrate that the amounts of total cellular. cytosolic, and microsomal enzyme diminish as lung maturation proceeds. Enzyme activity parallels enzyme mass in the microsomal fraction of lung tissue. This is not true, however, in the cytosol, which contains the bulk of both enzyme mass and activity; enzyme activity increases while enzyme mass decreases as a function of lung maturation.

Recent data suggest that microsomal cytidylyltransferase physically resembles the cytosolic $\mathrm{H}$-form species (32). Our observation that microsomal protein was not detected in the neonate and adult does not rule out the possibility that cytidylyltransferase antigen was present; most likely it was present at levels below the sensitivity of our assay system. Alternatively, it is possible. although unlikely, that particulate enzyme was not fully recovered after detergent extraction of the microsomal pellet (17). In contrast to the expression of microsomal enzyme, our studies show that high levels of cytosolic enzyme activity are preserved in the adult lung despite relatively low levels of immunoreactive protein. These findings in adult lung contrast with those in fetal lung, which contains much greater amounts of enzyme mass. These observations could be explained by a more efficient conversion of enzyme protein into $\mathrm{H}$-form species in the adult lung compared with the fetal lung. Alternatively, other posttranslational regulatory mechanisms. such as differences in phosphorylation of cytosolic enzyme, could explain these findings (14, 33). In addition, fatty acids $(17,18,34)$ and anionic phosphoglycerides $(26,35)$ are potent activators of cytidylyltransferase, and it is possible that these agents interact with the enzyme in a different manner in adult lung than in fetal lung.

To further evaluate the potential regulatory mechanisms underlying cytidylyltransferase function, we measured the amount of cytosolic H-form and L-form enzyme mass in fetal (d 20) and adult lungs. We found that, in adult lung, a substantial portion of the enzyme activity and enzyme mass was expressed as the $\mathrm{H}$ form of the enzyme. In the fetal lung, the enzyme activity was primarily expressed as the L-form of the enzyme. In addition, in marked contrast to the adult lung, over two thirds of fetal cytosolic enzyme mass was detected in the L-form fractions. These findings suggest that the fetal lung contains large amounts 
of relatively inactive enzyme. When we further analyzed our data in terms of sp act of enzyme using densitometric measurements of enzyme mass (Table 1), we observed that the relatively low levels of fetal and adult $\mathrm{H}$-form enzyme protein isolated in fraction I expressed the highest levels of catalytic activity. This likely is explained, at least in part, by prior observations that demonstrated that the fraction I species is highly lipid associated (26), accounting for both its large molecular size after separation and its kinetic properties.

Several studies suggest that phosphatidylglycerol may be an important activator of cytidylyltransferase during pulmonary maturation $(26,28,36,37)$. A 3 -fold increase in the lung content of phosphatidylglycerol occurs from the fetal to the newborn period (37). Phosphatidylglycerol increases phosphatidylcholine production (35) and stimulates cytidylyltransferase activity when this lipid is added either directly to the assay mixture $(36,38)$ or to the culture medium (35). The previous finding that this phospholipid is a component of $\mathrm{H}$-form enzyme (26), together with observations that phosphatidylglycerol converts the inactive form (L-form) to an active species (H-form) as determined by the elution profile of enzyme activity after chromatography (26), led us to examine whether this lipid activator had similar effects on enzyme mass. We first observed that exposure of fetal lung cytosol to sonicated preparations of phosphatidylglycerol resulted in a similar shift in activity from the relatively lower molecular weight fractions to the active high-molecular-weight species (Fig. 8) (26). Further, these physiologic changes in activity were also associated with a corresponding shift in enzyme mass from Lform to $\mathrm{H}$-form enzyme (Fig. 10). In the neonate, previous reports have demonstrated a 3-fold increase in the sp act of cytidylyltransferase after addition of phosphatidylglycerol to lung cytosol (28). Our results suggest that these stimulatory effects on neonatal enzyme may also involve aggregation of cytidylyltransferase protein into an active high-molecular-weight form. Phosphatidylglycerol in the present study induced a marked shift in enzyme mass from the L-form to $\mathrm{H}$-form species (Fig. 11). The phospholipid had more limited effects, however, on redistributing enzyme activity because in the 3-d-old neonate cytosolic enzyme was already expressed primarily as the active form (Fig. 12).

Overall, these studies suggest that the majority of cytidylyltransferase enzyme is highly active in the neonatal and adult lung, whereas most of the enzyme mass is relatively inactive in the fetal lung. This reservoir of physiologically inactive enzyme in the fetus appears to be converted to an active form by anionic phospholipid during perinatal development as the overall size of the lung increases.

Acknowledgments. The authors thank Dr. James Hunter and Sandy Shasby for their suggestions with regard to the gel filtration chromatography. We also thank Jeanne Hunter and Sandy Cosgrove for their secretarial assistance.

\section{REFERENCES}

1. Pelech SL, Vance DE 1984 Trifluoperazine and chlorpromazine inhibit phosphatidylcholine biosynthesis and CTP:phosphocholine cytidylyltransferase in HeLa cells. Biochim Biophys Acta 779:217-251

2. Sleight R, Kent C 1980 Regulation of phosphatidylcholine biosynthesis in cultured chick embryonic muscle treated with phospholipase C. J Biol Chem 255:10644-10650

3. Wright PS, Morand JN, Kent C 1985 Regulation of phosphatidylcholine biosynthesis in Chinese hamster ovary cells by reversible membrane association of CTP:phosphatidylcholine cytidylyltransferase. J Biol Chem 260: 7919-7926

4. Vance DE, Trip EM, Paddon HB 1980 Poliovirus increases phosphatidylcholine biosynthesis in HeLa cells by stimulation of the rate-limiting reaction catalyzed by CTP:phosphocholine cytidylyltransferase. J Biol Chem 255: 1064-1069

5. Oldenburg V, Van Golde LMG 1977 The enzymes of phosphatidylcholine biosynthesis in the fetal mouse lung. Biochim Biophys Acta 489:454-465
6. Rooney SA 1985 The surfactant system and lung phospholipid biochemistry. Am Rev Respir Dis 131:439-460

7. Stern W. Kovac C. Weinhold PA 1976 Activity and properties of CTP:cholinephosphate cytidylyltransferase in adult and fetal rat lung. Biochim Biophys Acta 441:280-293

8. Choy PC, Lim PH, Vance DE 1977 Purification and characterization of CTP:cholinephosphate cytidylyltransferase from rat liver cytosol. J Biol Chem 252:7673-7677

9. Feldman DA. Dietrich JW. Weinhold PA 1980 Comparison of the phospholipid requirements and molecular form of CTP:phosphocholine cytidyly]transferase from rat lung, kidney, brain, and liver. Biochim Biophys Acta 620:603-611

10. Feldman DA, Kovach CR, Dranginis PL, Weinhold PA 1978 The role of phosphatidylglycerol in the activation of CTP:phosphocholine cytidylyltransferase from rat lung. J Biol Chem 253:4980-4986

11. Rooney SA. Wai-Lee TS, Gobran L. Motoyama EK 1976 Phospholipid content, composition and biosynthesis during fetal lung development in the rabbit. Biochim Biophys Acta 431:447-458

12. Maniscalco WM. Wilson CM. Gross I, Gobran L, Rooney SA, Warshaw JB 1978 Development of glycogen and phospholipid metabolism in fetal and newborn rat lung. Biochim Biophys Acta 530:333-346

13. Chan F, Harding PGR. Wong T, Fellows GF. Possmayer F 1983 Cellular distribution of enzymes involved in phosphatidylcholine synthesis in developing rat lung. Can J Biochem Cell Biol 61:107-114

14. Sanghera J. Vance DE 1989 Phosphocholine cytidylyltransferase is a substrate for cAMP-dependent protein kinase in vitro. J Biol Chem 264:1215-1223

15. Post M 1987 Maternal administration of dexamethasone stimulates cholinephosphate cytidylyltransferase in fetal type Il cells. Biochem J 241:291-296

16. Jamil H. Yao Z. Vance DE 1990 Feedback regulation of CTP:phosphocholine cytidylyltransferase translocation between cytosol and endoplasmic reticulum by phosphatidylcholine. J Biol Chem 265:4332-4339

17. Weinhold PA. Charles L. Rounsifer ME, Feldman DA 1991 Control of phosphatidylcholine synthesis in Hep G2. cells. J Biol Chem 266:6093-6100

18. Aeberhard EE, Barrett CT. Kaplan SA. Scott ML 1986 Stimulation of phosphatidylcholine synthesis by fatty acids in fetal rabbit type II pneumocytes. Biochim Biophys Acta 875:6-11

19. Sanghera JS, Vance DE 1989 Stimulation of CTP:phosphocholine cytidylyltransferase and phosphatidylcholine synthesis by calcium in rat hepatocytes. Biochim Biophys Acta 1003:284-292

20. Weinhold PA, Rounsifer ME. Feldman DA 1986 The purification and characterization of CTP:phosphorylcholine cytidylyltransferase from rat liver. J Biol Chem 261:5104-5110

21. Yao Z, Jamil H, Vance DE 1990 Choline deficiency causes translocation of CTP:phosphocholine cytidylyltransferase from cytosol to endoplasmic reticulum in rat liver. $\mathrm{J}$ Biol Chem 265:4326-4331

22. Bradford M $1976 \mathrm{~A}$ rapid and sensitive method for the quantitation of microgram quantities of protein utilizing the principle of protein-dye binding. Ann Biochem 72:248-254

23. Laemmli UK 1970 Cleavage of structural proteins during the assembly of the head of bacteriophage T4. Nature 227:680-685

24. Ambrose MP. Hunninghake GW 1990 Corticosteroids increase lipocortin I in alveolar epithelial cells. Am J Respir Cell Mol Biol 3:349-353

25. Towbin H. Staehelin T. Gordan J 1979 Electrophoretic transfer of proteins from polyacrylamide gels to nitrocellulose sheets: procedure and some implications. Proc Natl Acad Sci USA 76:4350-4354

26. Feldman DA, Kovac CR, Dranginis PL. Weinhold PA 1978 The role of phosphatidylglycerol in the activation of CTP:phosphocholine cytidylyltransferase from rat lung. J Biol Chem 253:4980-4986

27. Choy PC, Schneider WJ, Vance DE 1978 Immunological studies on CTP:phosphocholine cytidylyltransferase from the livers of normal and choline-deficient rats. Eur J Biochem 85:189-193

28. Casola PG, Chan F, MacDonald PM. Ryan S, McMurray WC, Possmayer F 1980 Coordinate increases in the enzyme activities responsible for phosphatidylglycerol synthesis and CTP:cholinephosphate cytidylyltransferase activity in developing rat lung. Biochem Biophys Res Commun 96:1209-1215

29. Randell SH. Mercer RR. Young SL 1989 Postnatal growth of pulmonary acini and alveoli in normal and oxygen-exposed rats studies by serial section reconstructions. Am J Anat 186:55-68

30. Randell SH, Silbajoris R, Young SL 1991 Ontogeny of rat lung type II cells correlated with surfactant lipid and surfactant apoprotein expression. Am J Physiol 260:L562-L570

31. Weinhold PA. Rounsifer ME, Charles L, Feldman DA 1989 Characterization of cytosolic forms of CTP:choline-phosphate cytidylyltransferase in lung. isolated alveolar type II cells. A549 cells, and Hep G2 cells. Biochim Biophys Acta 1006:299-310

32. Feldman DA, Rounsifer ME, Charles L, Weinhold PA 1990 CTP:phosphocholine cytidylyltransferase in rat lung: relationship between cytosolic and membrane forms. Biochim Biophys Acta 1045:49-57

33. Watkins JD, Kent C 1990 Phosphorylation of CTP:Phosphocholine cytidylyltransferase in vivo. J Biol Chem 265:2190-2197 
34. Pelech SL. Pritchard PH. Brindley DN. Vance DE 1983 Fatty acids promote translocation of CTP:phosphocholine cytidylyltransferase to the endoplasmic reticulum and stimulate rat hepatic phosphatidylcholine synthesis. J Biol Chem 258:6782-6788

35. Gilfillan AM, Smart DA, Rooney SA 1985 Phosphatidylglycerol stimulates cholinephosphate cytidylyltransferase activity and phosphatidylcholine synthesis in type II pneumocytes. Biochim Biophys Acta 835:141-146

36. Chu AJ. Rooney SA 1985 Stimulation of cholinephosphate cytidylyltransferase activity by estrogen in fetal rabbit lung is mediated by phospholipids. Biochim Biophys Acta 834:346-356

37. Hallman M, Gluck L 1980 Formation of acidic phospholipids in rabbit lung during perinatal development. Pediatr Res 14:1250-1259

38. Rosenberg IL. Smart DA. Gilfillan AM, Rooney SA 1987 Effect of 1-oleoyl-2acetylglycerol and other lipids on phosphatidylcholine synthesis and cholinephosphate cytidylyltransferase activity in cultured type II pneumocytes Biochim Biophys Acta 921:473-480

\section{Announcement}

\section{Nominations for the 1994 E. Mead Johnson Award for Research in Pediatrics}

Nominations are invited for the 1994 E. Mead Johnson Award for Research in Pediatrics. Each of two recipients will receive an honorarium of $\$ 10,000$ plus travel expenses to attend the 1994 meeting of the Society for Pediatric Research in Seattle, WA, where recipients will present their research at a special seminar.

Eligibility for the 1994 award:

1) Nominees must have received their doctoral degree in 1974 or later

2) Limited to investigators in the Americas

3) Research is related to pediatrics and recently published, perhaps coming to fruition or attaining recognition during the past few years

Candidates are nominated by their Department Chairs or past E. Mead Johnson Award recipients. The deadline for submission is December 3, 1993. Nomination forms may be obtained from: Debbie L. Anagnostelis. The Society for Pediatric Research, P.O. Box 675, Elk Grove Village, IL 60009-0675. 